\title{
Presentation of the French Project DéCoF-Ré
}

\author{
Véronique Bouteiller \\ Université Paris-Est, MAST, EMGCU, IFSTTAR, 77447 Marne-la-Vallée, France
}

Lucas Bourreau

SIXENSE Concrete, Agence Ouest, F44115 Haute-Goulaine, France

Laurent Gaillet

Université Bretagne Loire, IFSTTAR, MAST, SMC, F44344 Bouguenais, France

\section{Franck Schoefs}

Université Bretagne Loire, Université de Nantes, GeM, UMR CNRS 6183, Research Institute in Civil Engineering and Mechanics, France, IUML FR CNRS 3473, Sea and Littoral research Institute, Nantes, France

\section{Benoit Thauvin}

Cerema Ouest, F22015 Saint-Brieuc, France

Julien Schneider

Cerema lle-de-France, F77171 Sourdun, France

Contact: veronique.bouteiller@ifsttar.fr

\begin{abstract}
A relevant knowledge of the state of the reinforced concrete is the basis for a successful management of the structures such as civil engineering bridges. To provide answers, IFSTTAR (coordinator), Cerema, Nantes University and Capacité SAS, SIXENSE-Concrete Company and the Département de la Charente-Maritime have contributed and funded a collaborative research project from 2015 to 2018. The French Project DéCoF-Ré meaning Decision Corrosion and Reliability of the ile de Ré Bridge has two main objectives. The first objective is to perform a reliable corrosion diagnosis of the piers of a bridge in a marine environment by means of non-destructive tests such as half-cell potential and resistivity. The second objective is to determine the durability of the concrete cover of the piers in terms of durability indicators. The aim of this paper is to present the Project DéCoF-Ré and to give some preliminary results.
\end{abstract}

Keywords: reinforced concrete, bridge, marine environment, corrosion diagnosis, concrete durability, chloride indicator 


\section{Introduction}

Corrosion is considered as the main degradation of reinforced concrete structures $([1,2]$. In France, being designed for a lifespan of 50 years, the reinforced concrete bridge average is 35 years old. At the level of bridge's owners a plan is needed to prioritize the maintenance or rehabilitation or retirement. At the level of researchers, reliable tools to assess the state of the reinforced concrete structure based on the corrosion diagnosis of the steel reinforcement together with the concrete durability are to be provided in order to qualify the state of the structure, to predict its durability and to suggest further repair solutions (patch repair or electrochemical treatments).

The French Project DéCoF-Ré meaning Decision Corrosion and Reliability of the ile de Ré Bridge has two main objectives. The first objective is to perform a reliable corrosion diagnosis of the piers of the bridge which is located in a marine environment by means of non-destructive tests such as half-cell potential and resistivity. The second objective is to determine the durability of the concrete cover of the piers in terms of durability indicators [3].

The aim of this paper is to present the French Porject DéCoF-Ré which is a collaborative research that started in 2015 involving six partners: IFSTTAR (coordinator), Cerema, Nantes University and Capacité SAS, SIXENSE-Concrete Company and the Département de la Charente-Maritime (owner of the ile de Ré Bridge).

\section{Presentation of the ile de Ré Bridge}

The ile de Ré Bridge (Figure 1), located in the French Atlantic coast, was built in 1987-1988 to provide an access to the Ré Island from La Rochelle mainland. The bridge has a total length of 2928.5 meters, a width of 15 meters and a maximum height above the sea level of 30 meters (shipping channel). The bridge deck was constructed on 28 piers, from which 24 piers were founded in the sea (Figure 2).

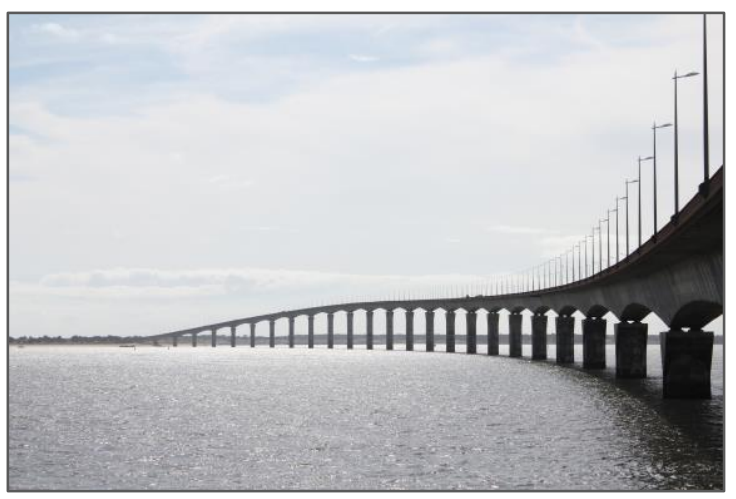

Figure 1: Ile de Ré Bridge (V. Bouteiller, Ifsttar)

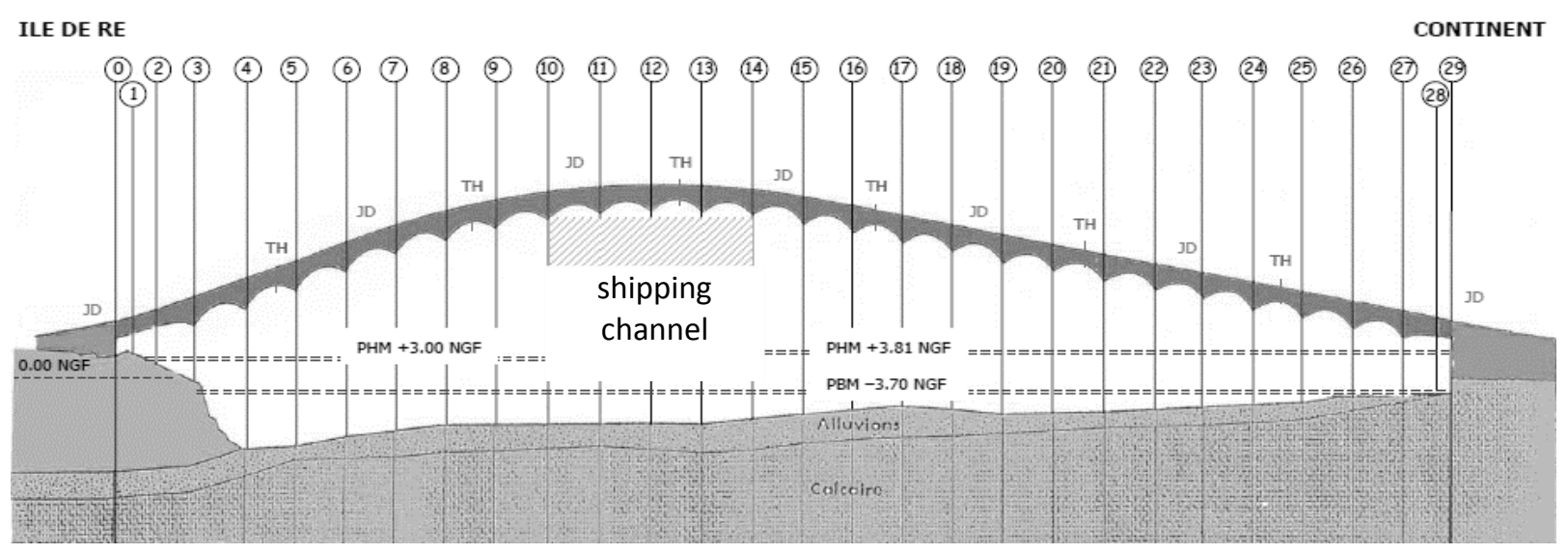

Figure 2. lle de Ré Bridge - longitudinal scheme

Piers concrete composition was based on a CPJ 45 RPM cement that today would correspond to a CEM II/B cement (Table 1) and the water/cement ratio was equal to 0.5 .
Table 1. Concrete mix composition (in $\mathrm{kg} / \mathrm{m}^{3}$ ) 


\begin{tabular}{ccccc}
\hline Cement & Water & $\begin{array}{c}\text { Sand } \\
\mathbf{0 / 3} \\
\mathbf{m m}\end{array}$ & $\begin{array}{c}\text { Gravel } \\
\mathbf{6 / 2 0} \\
\mathbf{m m}\end{array}$ & $\begin{array}{c}\text { Additive } \\
\text { Pozzolith } \\
\mathbf{2 0 0 N}\end{array}$ \\
\hline 370 & 185 & 830 & 1200 & 0.74 \\
\hline
\end{tabular}

The investigated area on a pier is described in Figure 3 and Figure 4.

Two faces (upon 8) of the piers were considered: face FC is the most exposed side with dominant winds (WSW for La Rochelle with $30 \mathrm{~km} / \mathrm{h}$ mean speed), daily sunshine and strongest wetting/drying cycles and face FG is the opposite side which is more sheltered (Figure 3 ).

Because the investigations needed to be performed using a vessel and depended on the tide duration, three zones defined in a coordinate system XOY (face's wide $1.85 \mathrm{~m}$ and height $1 \mathrm{~m}$ ) were studied corresponding to a total surface area of $5.55 \mathrm{~m}^{2}$ (Figure 4). These three zones includes atmospheric, splash and tidal exposures that can be related to the XS1 and XS3 exposure classes in marine environment according to the EN206 standard [4].

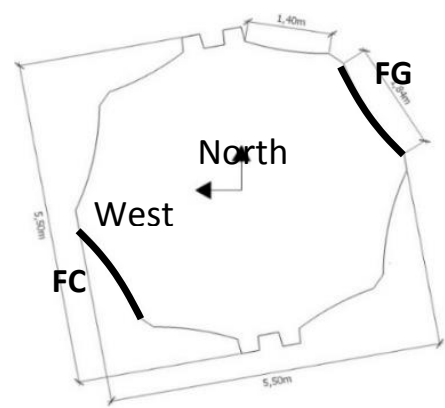

Figure 3. Top view of the pier with the investigated faces $F C$ and $F G$

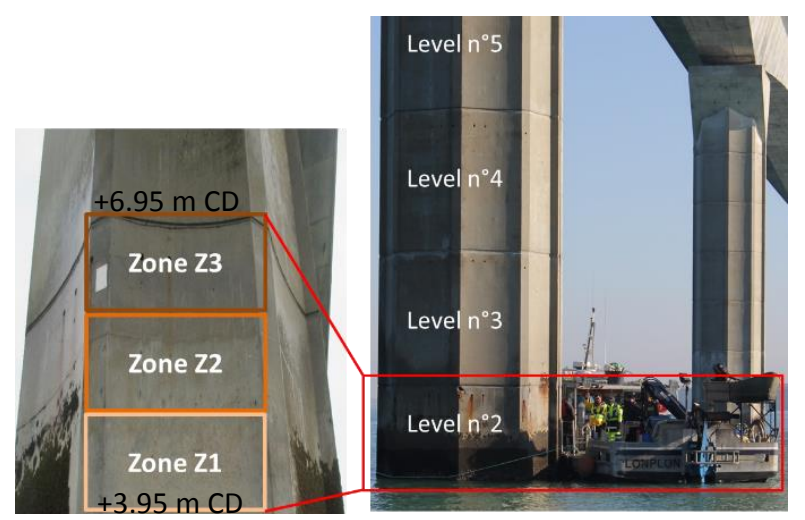

Figure 4. Investigated area with corresponding zones $\mathrm{Z1}, \mathrm{ZZ}$ and $\mathrm{Z3}$ and water heights $(C D=$ Chart Datum)

\section{Corrosion diagnosis}

Corrosion diagnosis was performed on 15 piers of the ile de Ré Bridge (14 in seawater using a vessel and 1 on the beach).

Corrosion diagnosis methodology was divided in six steps. The first step consisted in finding the general bridge's information from the archives. The following steps, illustrated in Figure 5, were performed using a vessel. The second step consisted in a visual inspection of the piers (after cleaning) to assess the general degradation state (rust spots, leachings, cracks, etc.). The third step aimed at locating the steel reinforcements (horizontal and vertical rebars) using a ground penetrating radar (EasyScan ${ }^{\circ} 1.6 \mathrm{GHz}, \mathrm{GSSI}$ ). In the fourth step, concrete electrical resistivity was measured using a Wenner probe $\left(\operatorname{Resipod}^{\bullet} 5 \mathrm{~cm}\right.$, PROCEQ). The fifth and sixth steps were dedicated to the electrochemical measurements, respectively half-cell potentials (Canin $^{+^{\circ}}$ (copper/saturated copper sulphate electrode (CSE, $+318 \mathrm{mV}$ vs NHE)), PROCEQ) and corrosion rates (GalvaPulse , Germann Instrument). 


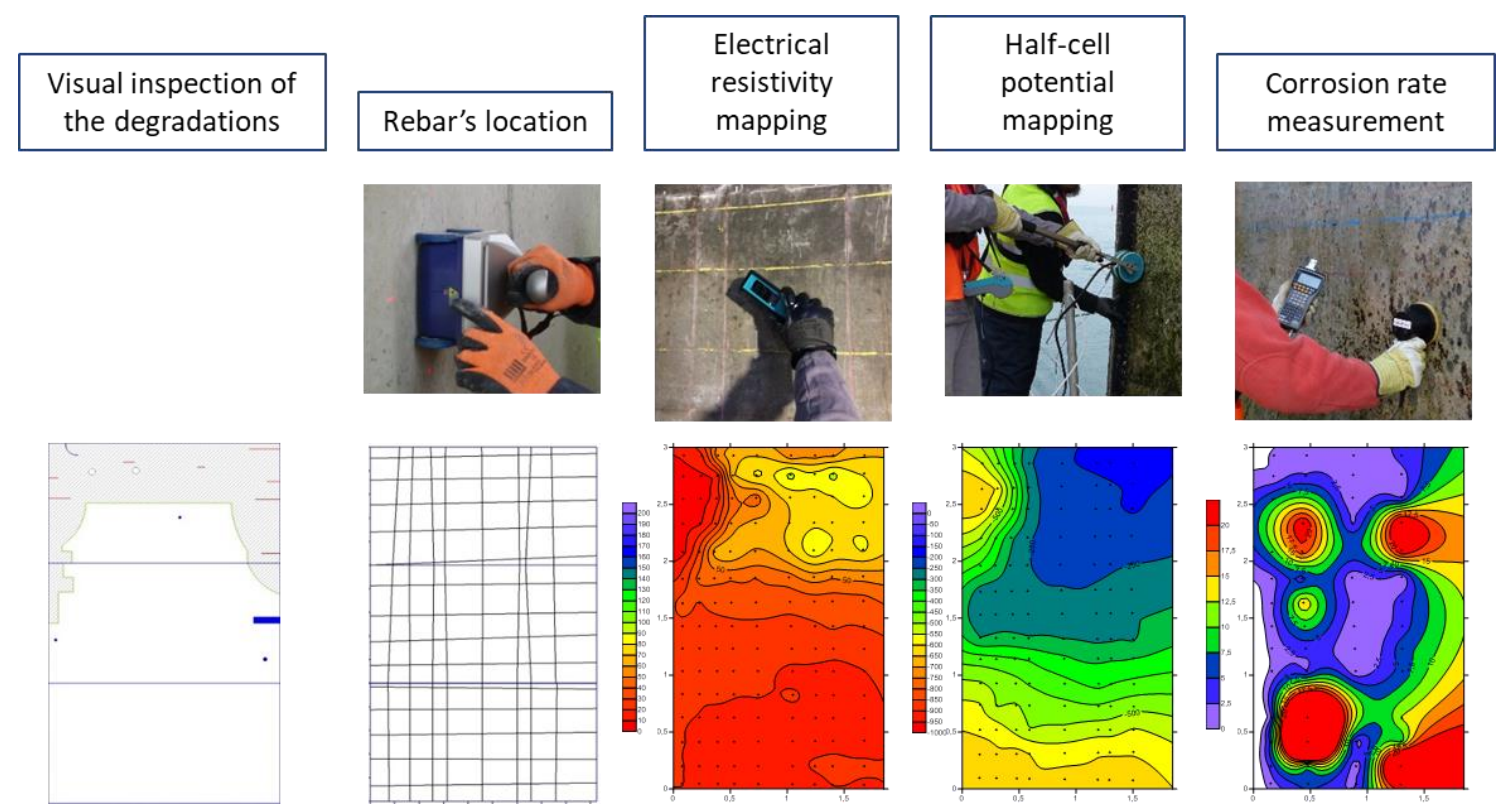

Figure 5. Methodology to assess the corrosion state of the steel reinforcement of the piers of the ile de Ré Bridge

\section{Durability of concrete}

After 29 years, the concrete durability of the piers of the ile de Ré Bridge was investigated on 11 piers (10 in seawater using a vessel and 1 on the beach). The durability of concrete is determined largely by its deterioration over time which is affected by the environment [3]. The study consisted, after drilling the cores from the structure, in determining the durability indicators (chloride migration tests, water porosity, gas permeability, capillary absorption and resistivity) and the penetration front of chlorides (Xd) as well as of carbonation (Xc).

\section{Preliminary results}

\subsection{Corrosion reliability}

The interpretation of measurement values according to different standards or literature recommendations [5-8]showed that the diagnosis can be erroneous because of the influence of the marine environment. In order to provide more reliable results, models of the influences of the tide, the water height and the seasons were therefore studied $[9,10]$.

As an example for the half-cell measurement interpretation, Figure 6 (left) presents the potential mapping as measured on the pier PN face FG during summer, considering the ASTM analysis [6]. This mapping shows a gradual increase of potential from the bottom zone to the top zone. From the literature it appears that the gradient is not significant of a decrease of probability of corrosion but is rather due to a lack of oxygen (mainly in the bottom zone). A model was then developed considering the average values of half-cell potentials for the horizontal reinforcements. Figure 6 (middle) shows the heights and their corresponding half-cell potentials "reference profiles" for faces FC and FG. Finally, a reliable potential mapping was obtained considering the raw measurements and subtracting the reference profiles. The resulting mapping is illustrated on Figure 6 (right). The investigated area finally appears like a no-active-corrosion region. 

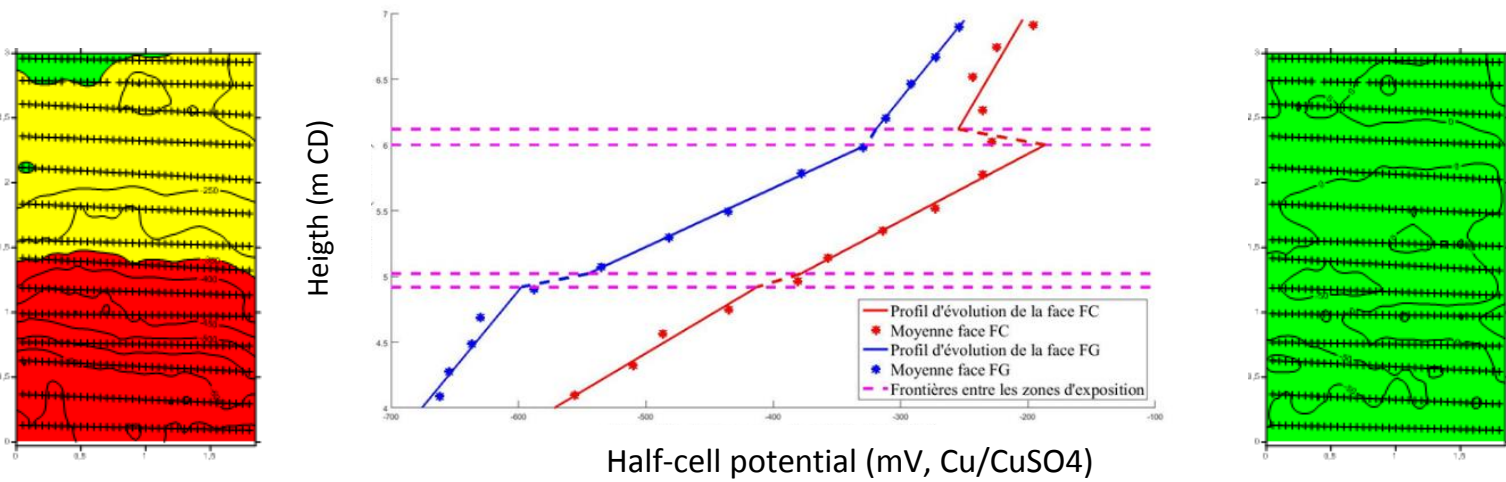

Figure 6. Potential mapping with ASTM C876 analysis (left), model of half-cell potential reference profiles (middle) and reliable potential mapping (right) for pile PN face FC

\subsection{Concrete durability}

In a marine environment, chloride ingress is one of the major causes of the premature deterioration of the reinforced concrete structures. From the durability point of view, when exceeding a certain amount of chloride at the rebar level, this latter can be depassivated and the corrosion initiating.

In the Project DéCoF-Ré, 51 cores were drilled from the structure to determine the chloride profiles depending on the pier, the face and the height. The penetration of chlorides was then compared to the concrete cover of the reinforcements.

As an example, Table 2 gathers the amount of free and total chlorides as determined by potentiometric titration for pier PN face FC for the three zones Z1, Z2 and Z3. The critical chloride content was considered equal to $0.4 \%$ weight of concrete as described in literature. The chloride content was higher than the critical chloride content for a concrete cover of $15-25 \mathrm{~mm}$ (the values appear in red) or $45-55 \mathrm{~mm}$ in the case of total chlorides for zone 1 . The chloride penetration index, $\mathrm{Xd}$, has been determined as the intersection of the chloride profiles and the critical chloride content and is also reported in Table 2. For the free chlorides Xd values are equal to 36,33 and $42 \mathrm{~mm}$ respectively for zones $Z 1, Z 2$ and $Z 3$. For the total chloride, $X d$ values become 59,48 and $47 \mathrm{~mm}$.

From Figure 7 which illustrates the concrete cover of horizontal and vertical reinforcements of pier PN face FC as determined by radar and an image analysis, the concrete cover values were in the range of 55 to $125 \mathrm{~mm}$.

For this pier, after 29 years, chlorides did not reach the reinforcement level and thus the corrosion is not alike to occur. This is in good agreement with the result from the reliable potential mapping (Figure 6 left).

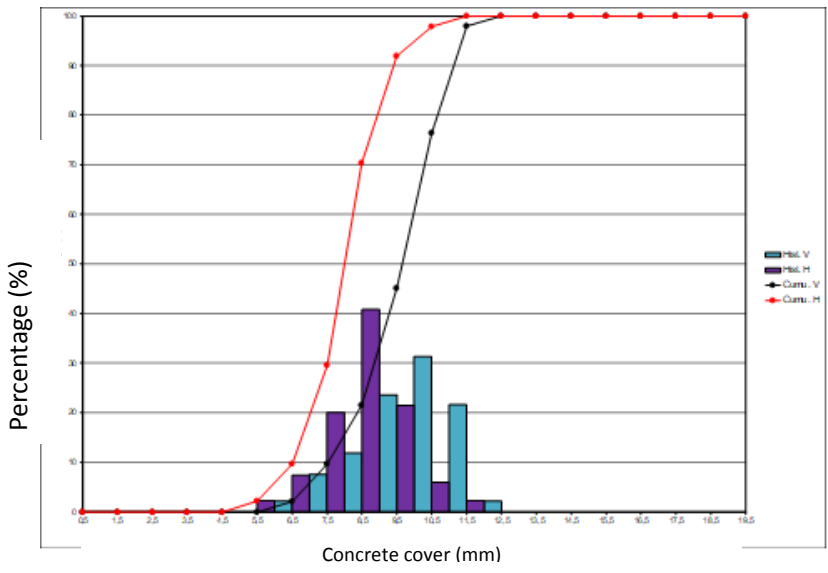

Figure 7. Concrete cover of horizontal and vertical reinforcements as determined by radar and image analysis for pier $P N$ face $F C$ 
Table 2. Free and total chloride content versus depth and chloride front $(X c)$; Critical chloride content is equal to $0.67 \%$ (according to concrete formulation and density).

\begin{tabular}{cccccc} 
& \multicolumn{2}{c}{ Free chlorides (g/100g of concrete) } & \multicolumn{2}{c}{} \\
Depth (mm) & $05-15$ & $15-25$ & $45-55$ & $75-85$ & Xd free \\
\hline PN-FC-Z3-X80cm-Y67cm & 0,26 & 0,18 & 0,02 & 0,01 & 42 \\
PN-FC-Z2-X110cm-Y66cm & 0,17 & 0,09 & 0,02 & 0,00 & 33 \\
PN-FC-Z1-X110cm-Y68cm & 0,16 & 0,09 & 0,04 & 0,00 & 36 \\
& Total chlorides (g/100g of concrete) & & \\
Depth (mm) & $05-15$ & $15-25$ & $45-55$ & $75-85$ & Xd total \\
\hline PN-FC-Z3-X80cm-Y67cm & 0,44 & 0,36 & 0,03 & 0,01 & 47 \\
PN-FC-Z2-X110cm-Y66cm & 0,35 & 0,20 & 0,05 & 0,01 & 48 \\
PN-FC-Z1-X110cm-Y68cm & 0,28 & 0,18 & 0,08 & 0,02 & 59
\end{tabular}

\section{Conclusions}

The results of the DéCoF-Ré Project have been gathered in two databases, one dealing with the corrosion diagnosis and a second one dealing with the durability of the concrete cover.

Corrosion results have been modelled in order to provide reliable mappings of half-cell potentials considering the influences of the tide, the height and the seasons.

The durability results have been analysed in terms of chloride profiles and compared to the concrete cover of the reinforcements.

More work is under progress and the state of the piers of the ile de Ré Bridge will be ascertained based on the complementary analysis of corrosion results and durability results. Furthermore, the autopsies performed on several locations will allow to validate the conclusions.

\section{Acknowledgements}

The authors would like to thank the team of the DéCoF-Ré Project: B. Godart, W. Traverst, P. Boujard, N. Coulaty-Chin, A. Orcesi, Y. El Rabbih, X. Derobert, M. Sissoko (IFSTTAR); R. Queguiner, S. Pasquiet, P. Boulaire, M. Rebours, C. Naudat (Cerema Dter Ouest); F. Landrin and V. Queyrat (Cerema Dter lle de France), J-F. Barthélémy (Cerema Dtec ITM); M. Roche, O. Amiri (Nantes University); M. Brouxel, S. Naar (SIXENSEConcrete), A. Audouin-Dubreuil, F. Lavoute, M. Barbier (Département de la Charente-Maritime); F.
Gazet (Dekra). They also thank the team of the vessel for their help.

\section{References}

[1] Woodward R, Cullington DW, Daly AF, Vassie PRW, Haardt $P$, Kashner $R$, et al. Bridge management in Europe (BRIME)-Deliverable D14Final Report. 2001. p. 228.

[2] Tilly GP, Jacobs J. CONREPNET - Concrete repairs - Performance in service and current practice. United Kingdom: IHS BRE Press; 2007.

[3] Etat de l'art et guide pour la mise en oeuvre d'une approche performantielle et prédictive sur la base d'indicateurs de durabilité2004.

[4] AFNOR. NF EN 206-1 / P18-325-1. Béton : spécification, performances, production et conformités. 2004.

[5] ASTM. C 876-91, Standard test method for halfcell potentials of uncoated reinforcing steel in concrete. ASTM; 1999.

[6] ASTM. C 876-09, Standard test method for halfcell potentials of uncoated reinforcing steel in concrete. ASTM; 2009.

[7] Cox RN, Cigna R, Vennesland O, Valente T, (Eds). COST 509 - Corrosion and protection of metals in contact with concrete - Final Report: European Commission, Directorate General Science, Research and Development, Brussels, EUR 17608 EN; 1997. 
[8] Elsener B. RILEM TC 154-EMC:Electrochemical Techniques for Measuring Metallic Corrosion Recommendations - Half-cell potential measurements - Potential mapping on reinforced concrete structures. Materials and Structures. 2003;36:461-71.

[9] Bourreau L. Diagnostic de corrosion sur ouvrage - Fiabilité et aide à la décision: Thèse de l'Université de Nantes, France; 2017.

[10] Bourreau L, Bouteiller V, Schoefs F, Gaillet L, Thauvin B, Schneider J, et al. On-site corrosion monitoring - reliability. Materials, Systems and Structures in Civil Engineering Conference, Segment on Electrochemistry in Civil Engineering. Technical University of Denmark, Lyngby, Denmark 2016. 